\title{
ROTACIÓN DE SUBSECRETARIOS EN CHILE: UNA EXPLORACIÓN DE LA SEGUNDA LÍNEA GUBERNAMENTAL, 1990-2014*
}

\author{
Bastián González-Bustamante \\ Universidad de Santiago de Chile, Chile \\ bastian.gonzalez.b@usach.cl \\ Alejandro Olivares Lavados \\ Universidad de Chile, Chile \\ aleolivares@iap.uchile.cl
}

\section{RESUMEN}

Este artículo analiza la rotación y supervivencia de los subsecretarios en Chile durante los gobiernos de la Concertación (1990-2010) y el gobierno de Sebastián Piñera (2010-2014). Durante la última década los gabinetes como objeto de estudio han ganado centralidad entre los académicos que estudian el funcionamiento presidencial y aquellos que estudian las élites políticas. En este contexto, el presente trabajo analiza un objeto de estudio que ha sido ignorado: los subsecretarios, la segunda línea gubernamental. Se examina de forma descriptiva la rotación de todos los subsecretarios del período y con análisis de supervivencia, específicamente modelos de riesgos proporcionales, se evalúa la influencia de factores institucionales y eventos críticos (shocks), como tipo de dependencia ministerial, baja aprobación presidencial, escándalos de corrupción, entre otros, sobre la permanencia de los subsecretarios en sus cargos. Los hallazgos de este artículo permiten reflexionar sobre factores que son parte e influyen en el sistema político y emergen como predictores de riesgo/supervivencia en las subsecretarías. Esto hace que este trabajo sea una contribución original a la generación de conocimiento sobre el rol que han jugado los subsecretarios dentro del aparato gubernamental.

Palabras clave: Gabinetes, Élites, Subsecretarios, Rotación de personal, Chile.

* Esta investigación ha sido apoyada por el proyecto Fondecyt 1140564. Agradecemos especialmente a Sergio Toro, Investigador principal de aquel proyecto. Los avances preliminares de esta investigación fueron presentados en el Congreso Internacional Élites y Liderazgo en Tiempos de Cambio en la Universidad de Salamanca (Salamanca, junio de 2015) y en el VIII Congreso de la Asociación Latinoamericana de Ciencia Política (ALACIP) en la Pontificia Universidad Católica del Perú (Lima, julio de 2015). También agradecemos especialmente a Carla Cisternas por su apoyo en la validación de los datos presentados en España y Perú. 


\title{
UNDERSECRETARIES ROTATION IN CHILE: AN EXPLORATION OF THE SECOND GOVERNMENT LINE, 1990-2014
}

\begin{abstract}
This article analyzes the rotation and the survival of undersecretaries in Chile during the governments of the Concertación (1990-2010) and the government of Sebastián Piñera (2010-2014). During the last decade cabinets as an object of study have earned centrality among scholars who study the presidential functioning and those who study political elites. In this context, this paper analyzes an object of study that has been overlooked: the undersecretaries, the second government line. Descriptively it examines the rotation of all undersecretaries of the period and with survival analysis, specifically proportional hazards models, the influence of institutional factors and critical events (shocks) as a kind of ministerial dependency, low presidential approval, corruption scandals are evaluated, among others, in relation with the permanence of the undersecretaries in office. The findings of this article allow a thought about factors that are part and influence the political system and emerge as predictors of risk/survival in the undersecretariats. This makes this work an original contribution to the generation of knowledge about the role that undersecretaries have played within the government apparatus.
\end{abstract}

Keywords: Cabinets, Elites, Undersecretaries, Staff rotation, Chile. 


\section{INTRODUCCIÓN}

La mayoría de la investigación sobre personal político, en el contexto de los sistemas presidenciales, se centra en los cargos de primera línea: presidentes, ministros, senadores y diputados. La predilección y casi obsesión por aquellos objetos de estudio es comprensible ya que son las posiciones formales más relevantes en el ámbito gubernamental en los sistemas políticos contemporáneos, sin embargo, implica una externalidad negativa: no prestar atención a los actores que están desarrollando una carrera política ${ }^{1}$, es decir, aquellos que tienen la posibilidad de llegar a esos cargos. El desinterés se funda en que dicho objeto de estudio es un contrafactual y sucede una situación similar a lo que ocurre en los estudios electorales: la mayoría estudia a los incumbentes y a los ganadores, muy pocos prestan atención a lo que ocurre con aquellos que perdieron. Sin embargo, es limitado considerar a otras posiciones menos relevantes en términos jerárquicos solo como contrafactuales, pues pueden ser posiciones clave en la articulación entre el mundo político y la burocracia gubernamental. Por otra parte, también pueden ser posiciones invisibilizadas pero relevantes en la estructura de la carrera política o rutas hacia el poder en un sistema.

Las carreras políticas se asocian a curvas de aprendizaje sobre el quehacer del campo político y los asuntos públicos. En este contexto, el acceso a las posiciones más importantes en la élite política constituye un punto central en la carrera de todo individuo y para que esto ocurra se debe dar un proceso de acumulación de diversos recursos y capitales en el marco de una red social (Espinoza 2010, González-Bustamante 2013b). Una de las posiciones que entrega mayor experiencia en gestión administrativa en el quehacer gubernamental, y que además requiere de importantes recursos y capitales ya que se obtiene por designación presidencial, es el cargo de subsecretario (viceministro). Desde un punto de vista jurídico y técnico los subsecretarios son colaboradores inmediatos de los ministros. Su labor consiste en la coordinación de la acción de los órganos y servicios públicos de su sector, además actúan como ministros de fe, ejercen la administración interna del ministerio, tienen calidad de jefe de servicio y están facultados para subrogar al ministro respectivo ${ }^{2}$. A pesar de ser agentes centrales para el proceso político en Chile, especialmente por el rol que juegan en el

1 La carrera se entiende como la trayectoria política o cursus honorum de un individuo (Alcántara 2013). En este contexto, una carrera en desarrollo se relaciona con la idea de trayectoria ascendente: aquella donde el individuo aún no alcanza la cúspide del poder.

2 Para más detalles legales, véase la ley 18.575, específicamente el artículo 21. 
marco de la ejecución de políticas públicas, la literatura académica sobre el tema es prácticamente inexistente.

Este trabajo constituye una contribución significativa pues examina la rotación de subsecretarios en Chile entre 1990 y 2014. Si bien esto es importante porque el tema ha sido ignorado por el mundo académico, es también relevante porque los subsecretarios son la primera autoridad administrativa en el aparato gubernamental, por lo tanto su nivel de rotación y supervivencia puede impactar directamente sobre la gestión pública. Con análisis de supervivencia, específicamente modelos de riesgos proporcionales con fragilidad compartida, se evalúa la influencia de factores institucionales y eventos críticos (shocks) sobre la permanencia de los subsecretarios en sus cargos. El artículo se divide en cinco secciones. La primera es un apartado teórico donde se profundiza sobre teoría de élites, relación entre política y administración y el estudio de los gabinetes. La segunda sección ofrece un breve contexto político del período que abarca esta investigación (1990-2014). La tercera sección corresponde a un apartado metodológico donde se ofrecen detalles sobre el trabajo empírico realizado: detalles de los datos utilizados, operacionalización de variables, especificación de los modelos estadísticos usados, entre otros temas. La cuarta sección presenta los resultados en tres dimensiones: 1) resultados generales de orden descriptivo; 2) análisis de clúster por períodos, tasas de incidencia y rotación y estimaciones Kaplan-Meier; y 3) resultados de las modelaciones con regresiones de Cox con fragilidad compartida. Finalmente, el último apartado corresponde a las conclusiones donde se retoman las hipótesis de trabajo y se evalúa su comprobación o refutación a la luz de los datos presentados.

\section{CONTEXTO TEÓRICO: ÉLITES, TECNOCRACIA Y GABINETES}

El estudio de las élites políticas ha sido relevante para la sociología y la ciencia política desde principios del siglo XX. Diversos tópicos han sido subordinados a este tema: distribución del poder, carreras políticas y profesionalización, circulación del personal y agentes, entre otros. Las élites políticas son fácilmente identificables porque están altamente organizadas y ocupan posiciones de poder visibles en distintas instituciones (Uriarte 1997). Una de las posiciones más relevantes en las democracias contemporáneas es la de ministro de Estado, la cual ha inspirado toda una tradición de estudio que proviene principalmente de Europa, y se vincula estrechamente al estudio de los regímenes parlamentarios y las coaliciones en aquellos sistemas. 
En América Latina los trabajos sobre las élites son escasos y, en general, recientes. Esto se explica porque los procesos de modernización nacional y las olas de quiebres democráticos de la segunda mitad del siglo XX limitaron las agendas de investigación académica. De hecho, por mucho tiempo la principal y casi única obra de referencia sobre élites latinoamericanas fue la compilación de Lipset y Solari (1967), que recoge diversas colaboraciones de la cuales la mayoría en estricto rigor no se enfocan en élites, sino más bien en clases medias, campesinado e instituciones de la región. El impulso por estudiar las élites crece con la caída de los regímenes autoritarios, ya que se buscó analizar el rol que tuvieron algunas personas y grupos en las transiciones democráticas. Aquí los trabajos de Best (2011), Higley y Gunther (1992) y Higley y Pakulski (1992) marcaron una tradición de estudio con énfasis en los mecanismos de recuperación y mantención de las nuevas democracias. En la medida que la democracia como forma de gobierno se consolidó y los temas de investigación se reorientaron, aparecieron nuevos enfoques para situar a las élites en la discusión. Por ejemplo, la compilación de Birle, Hofmeister, Malhold y Potthast (2007) analiza, desde una perspectiva histórica, el rol de las élites en los diversos procesos vividos en América Latina, siendo una obra de referencia sobre las evoluciones de los grupos que han ejercido el poder en la región ${ }^{3}$.

Recientemente destacan investigaciones que examinan la composición y circulación de los agentes, como también su nivel de profesionalización. Ejemplos de esto son Cabezas (2011) sobre Bolivia, Colombia y Perú, y Espinoza (2015) sobre Bolivia. En Brasil es relevante el trabajo de Codato (2015) sobre élites políticas regionales. En Argentina se encuentran, por una parte, trabajos como Morresi y Vommaro (2014), con foco en los cuadros dirigentes pertenecientes a la Propuesta Republicana $(\mathrm{PRO})^{4} \mathrm{y}$, por otra parte, trabajos como Canelo (2011) y Levita (2015), que, desde la sociología política, se centran en los perfiles y las carreras de los senadores nacionales, o Lodola (2009) y Mustapic (2000) que, con un enfoque institucionalista, abordan aquel tema desde la ciencia política.

3 Del mismo modo, y como consecuencia de la gran influencia del Proyecto de Élites Parlamentarias Latinoamericanas (PELA) de la Universidad de Salamanca, se han desarrollado interesantes reflexiones sobre la profesionalización de la política y otros temas como las brechas ideológicas que existen dentro de la élite y entre ésta y la ciudadanía. Buenos de ejemplos de esto son Alcántara (2012), Alcántara y Luna (2004) y Luna y Zechmeister (2005).

4 También existen trabajos recientes enfocados en las élites conservadoras de otros países de la región. Para Chile véase Siavelis (2014) y para Brasil véase Montero (2014). 
En Chile el estudio de las élites políticas ha estado marcado por un desinterés del mundo académico, con excepción de casos más bien aislados provenientes desde la historia y la sociología (González-Bustamante 2013a, Joignant y Güell 2011) $)^{5}$. Sin embargo, esta situación ha cambiado bastante en los últimos años y es posible identificar una primera ola de literatura reciente donde Joignant (2011a, 2011b, 2011c, 2012), Silva (2006, 2010, 2011), Delamaza (2011) y Espinoza (2010) han tenido una influencia importante y han inspirado una segunda ola compuesta por trabajos con un fuerte foco empírico, entre los cuales se encuentran González-Bustamante (2013b, 2014), Joignant (2014), Lobos (2014) ${ }^{6}$. En este grupo de trabajos cabría esperar algún tipo de análisis sobre los subsecretarios por su rol en el proceso político. No obstante, los subsecretarios son nombrados como un actor más, sin profundizar sobre su composición como grupo y sus características como parte de la élite política.

Por otra parte, se encuentra la literatura que estudia la relación entre política y técnica, donde tiene cabida la discusión teórica sobre burocracia, tecnocracia y procesos políticos. Este tipo de trabajos también tiende a dejar fuera a los subsecretarios, y cuando son incluidos se hace como un ejemplo de politización de la gestión o de tecnificación de la política. Una de las posibles explicaciones sobre la existencia de este vacío es que los subsecretarios, a pesar de su naturaleza política, son considerados más bien como funcionarios y no políticos precisamente. Esto sucede por la dualidad de funciones propias de esta posición. Desde este punto de vista pareciera que existe una distancia entre el mundo político, ministros principalmente, y los funcionarios públicos -ya sean estos burócratas, tecnócratas o altos

5 Entre aquellas excepciones es relevante agregar y destacar el trabajo de Reimer (1970). Esta investigación pionera se enfoca en medir la circulación de la élite política en Chile con base en una fórmula de velocidad con la cual analiza 2.110 cargos ocupados por 1.710 individuos en 47 instituciones a través de seis cortes decenales (1917, 1927, 1937, 1947, 1957 y 1967). Establece cuatro categorías de acuerdo a la velocidad de circulación: alta, mediana, normal y baja. No se registran gobiernos de baja circulación. El gobierno de Eduardo Frei Montalva, por ejemplo, tiene una circulación normal. En el rango de circulación mediana se encuentra, por ejemplo, el gobierno de Jorge Alessandri Rodríguez (1958-1964). En el rango de alta circulación se encuentran los dos gobiernos de Arturo Alessandri Palma (1920-1924 y 1932-1938), los gobiernos radicales de la década de 1940, el gobierno de Carlos Ibáñez del Campo (1952-1958), entre otros.

6 También se podrían incluir en este grupo trabajos como Olivares, GonzálezBustamante, Meneses y Rodríguez (2014) y Olivares, Baeza y Dávila (2015), que se enfocan en los gabinetes ministeriales en Chile. 
directivos ${ }^{7}$.

Sería factible entonces que los subsecretarios fuesen objeto de estudio de otro tipo investigaciones vinculadas directamente con el análisis de los burócratas, tecnócratas o altos directivos. Los estudios de administración pública, por ejemplo, se centran en la figura del directivo público y tienden a dejar de lado a los subsecretarios, ya que los consideran agentes políticos. Por otra parte, cuando se analizan los debates teóricos sobre los procesos de modernización del Estado nuevamente los subsecretarios son excluidos, a pesar de que gran parte de esta literatura se centra en aspectos donde su quehacer es relevante: la relación entre técnica y política, la cual se manifiesta frecuentemente en la tensión existente entre política y gestión. En este contexto, los subsecretarios, como jefes de servicio, deben velar por el cumplimiento de la misión del servicio público, para lo cual deben seguir las directrices que emanan desde los ministros, los que a su vez siguen las directrices presidenciales. Entonces es factible suponer que los nombramientos de subsecretarios debiesen obedecer a criterios puramente técnicos y no políticos, esto porque su labor es eminentemente profesional. Sin embargo, lo anterior puede generar una captura y un dominio tecnocrático alejado de los ideales democráticos y las lógicas de representación asociadas a los nombramientos basados en confianza (Dávila 2010, 2011, González-Bustamante 2013a).

La confianza política es un elemento central en el proceso de nombramiento de ministros y subsecretarios. Los nombramientos se rigen por mecanismos informales de distribución de poder. La priorización de la confianza como criterio se asocia a los sistemas de botín (spoil systems), donde el clientelismo juega un rol fundamental. De hecho, el surgimiento de los sistemas de servicio civil se relaciona a una arquitectura institucional donde las credenciales académicas fueron de gran relevancia para obtener posiciones de privilegio en el aparato gubernamental, situación que benefició a élites políticas y sociales, ejemplos de esto son Gran Bretaña, Francia, Japón y Rusia (Grindle 2012). Los sistemas de servicio civil tienen características y especificidades determinadas que encuadran las relaciones y redes entre funcionarios públicos y políticos. Los grados de apertura de

7 Tradicionalmente los burócratas de alto nivel han sido denominados mandarines por encontrase insertos en un contexto de burocracia weberiana, donde la imposibilidad de remoción generaba que burócratas capturasen a los agentes políticos (GonzálezBustamante, Olivares, Abarca y Molina 2016). Por otra parte, términos como tecnócrata han sido utilizados para referirse a burócratas con altos niveles de recursos técnicos, es decir, credenciales académicas de alto prestigio. Por último, el término alto directivo es más propio del enfoque de Nueva Gestión Pública (NGP). 
un sistema y la tensión entre profesionalización y politización son ejes que impactan directamente en su tipificación (González-Bustamante et al. 2016, Ramió Matas y Salvador 2005). Los sistemas cerrados se basan en carreras funcionarias de por vida, los sistemas abiertos o de entrada lateral, en cambio, realizan selección con base en la especialización de los funcionarios. En este contexto, cabe preguntarse si las subsecretarías debiesen entrar en la lógica de los sistemas de servicio civil dado su carácter y responsabilidades técnicas y administrativas asociadas con la gestión de los ministerios ${ }^{8}$.

Por último, se encuentra la literatura asociada a los gabinetes, la cual se vincula a los subsecretarios ya que se centra específicamente en su superior jerárquico inmediato: los ministros. La tradición del estudio de los gabinetes y la rotación ministerial proviene principalmente de Europa y del estudio de los regímenes parlamentarios. Entre los trabajos clásicos se encuentran Blondel (1988), Blondel y Müller-Rommel $(1993,1997)$ y Blondel y Thiébault $(1988,1991)^{9}$. Por otra parte, entre los estudios más recientes destacan Curtin (2015) sobre el parlamentarismo neozelandés, Dowding y Lewis (2015) sobre el caso australiano que posee un gobierno federal estilo Westminster, y Masuyama y Nyblade (2015) que abordan el caso japonés que cuenta con un parlamentarismo de larga data. En América Latina destacan trabajos sobre el caso argentino, brasileño y uruguayo ${ }^{10}$. En Chile son relevantes las investigaciones de Olivares et al. (2014), Olivares et al. (2015), entre otros trabajos ${ }^{11}$.

8 Por ejemplo, en Espańa los subsecretarios son profesionales de carrera a los cuales se les exige grados académicos o títulos profesionales según el área de especialización de cada cartera.

9 También es relevante destacar el trabajo de King, Alt, Burns y Laver (1990), que propone un modelo estadístico unificado para explicar la disolución de los gabinetes en las democracias parlamentarias con base en variables relacionadas con los atributos de cada país, del sistema de partidos y de cada gabinete.

10 Sobre Argentina destacan los trabajos de Camerlo (2013), Canelo (2014) y Giorgi (2014). Sobre el caso brasileño resultan relevantes los trabajos de Amorim Neto (2000), Batista (2013) e Inácio (2013). Por último, sobe Uruguay se encuentra el trabajo de Chasquetti, Buquet y Cardarello (2013).

11 Destacan los trabajos descriptivos sobre gabinetes de la Concertación de Avendaño y Dávila (2012) y Dávila, Olivares y Avendaño (2013). Además se encuentra el reciente trabajo de Cuevas, Morales, Rojas y Aubry (2015), enfocado también en los ministros de la Concertación. Cuevas et al. (2015) utilizan un modelo logístico y análisis de supervivencia. Si bien esto resulta interesante, como trabajan con una submuestra 
Los gabinetes corresponden al conjunto de ministros nombrados por el jefe de gobierno para trabajar en el diseño y ejecución de políticas públicas. Los ministros que ingresan al gabinete deben demostrar capacidad de gestión y fijar prioridades, las cuales emanan desde el jefe de gobierno. Los ministros tienen la responsabilidad política del diseño de las políticas públicas. Siempre son de confianza de la autoridad del poder ejecutivo (Mainwaring 1993). Por otra parte, su contraparte, los subsecretarios, tienen responsabilidades administrativas y relacionadas con la ejecución de políticas. Dogan (1981) indica que la designación de ministros es un evento crucial para la vida política de todos los países, esto también es aplicable para la designación de subsecretarios ya que ambos procesos están estrechamente vinculados.

Como los subsecretarios poseen la potestad de subrogar a los ministros, resulta plausible suponer que operan mecanismos similares para el acceso y la permanencia en el campo. Además, ambos cargos están asociados a tiempos o momentos diferentes en la carrera política: un ministro es un político relativamente consagrado con amplios capitales y redes; el subsecretario, en cambio, generalmente es un político cuya carrera está en desarrollo y por lo tanto es altamente probable que en momentos posteriores -generalmente ańos después- asuma como ministro ${ }^{12}$. El proceso de conformación del gabinete no solo se rige por normas legales

de ministros es altamente probable que sus análisis estadísticos tengan fuertes sesgos, sobre todo los modelos de riesgos proporcionales. Por otra parte, la submuestra que utilizan y que forma parte de la base de datos del proyecto de investigación Fondecyt 1100877, no es adecuada y contiene errores. Los datos fueron revisados y validados en septiembre de 2014 (Joignant y González-Bustamante 2014, véase también GonzálezBustamante 2015) y Cuevas et al. (2015) no utilizan la base validada.

12 Esto está asociado a la idea de una carrera política ascendente. Puede ocurrir lo contrario, que un exministro eventualmente asuma como subsecretario, pero es algo poco común pues sería visto como un retroceso en la carrera. Para políticos profesionales el orden no necesariamente es importante, pues están disponibles para asumir cargos cuando el partido o el presidente lo necesite. En el caso chileno destacan Adriana Delpiano y Sergio Galilea. Delpiano luego de ser ministra en Bienes Nacionales (1994-1999) y en el Servicio Nacional de la Mujer (2000-2003), asumió como subsecretaria de Desarrollo Regional (2003-2006), luego como intendenta de la Región Metropolitana (2007-2008) y luego como ministra de Educación (2015 a la fecha). Galilea fue subsecretario de Vivienda (1994-1996), subsecretario del Ministerio Secretaría General de la Presidencia (Segpres) (1996-1999), ministro de Bienes Nacionales (1999-2000), intendente de la Región Metropolitana (20002001), intendente de la Región de Los Lagos (2008-2010) y luego asumió como subsecretario de Obras Públicas (2014 a la fecha). 
y formales, se trata de un proceso influido por un conjunto de reglas "no escritas" relevantes y que generalmente son conocidas por los principales actores del sistema político. Por esto buena parte de la literatura sobre gabinetes ha buscado identificar cuáles son aquellas reglas informales que condicionan a los sistemas políticos. De acuerdo a Altman (2000), existen dos teorías que explican cómo se realiza la distribución de ministerios entre los miembros de la coalición: primero, la distribución se realiza de forma proporcional a la cantidad de escaños que controla cada partido; segundo, el presidente podría reservar una cuota de cargos para distribuirlos entre su círculo de confianza ${ }^{13}$. Es plausible suponer que estas reglas aplican para la conformación de las subsecretarías.

Una arista importante es la salida de los titulares de sus cargos, situación que implica un ajuste en el gabinete. Estos ajustes tienen impacto a nivel de ministros y subsecretarios. En los regímenes presidenciales la decisión de realizar ajustes en el gabinete recae de forma casi exclusiva en el presidente (Mainwaring 1993). Independiente del régimen de gobierno, los cambios en los gabinetes son ajustes para enfrentar algún tipo de contingencia como la proximidad de una elección o un evento crítico que afecta el sistema político. La literatura tiende a identificar las crisis económicas, la baja popularidad y los escándalos mediáticos como shocks que aumentan el riesgo de rotación ministerial (Camerlo y Pérez-Liñán 2015, Martínez-Gallardo 2014). Además una rotación generalmente implica un reordenamiento de las fuerzas políticas en el aparato gubernamental en varios niveles.

En resumen, la investigación académica desde la teoría de las élites, la relación entre política y técnica, y los estudios de gabinetes, no se ha enfocado en la figura de los subsecretarios. Esto a pesar de que su nombramiento o salida puede suceder por causas similares que las que afectan la conformación y rotación ministerial. Los subsecretarios al igual que los ministros son miembros de élite política, pero no han sido estudiados como tales ni en Chile ni en la región. Por otra parte, los subsecretarios podrían haber sido incluidos en la agenda de investigación sobre la modernización del servicio público, pero esto tampoco ha ocurrido. En suma, no obstante su centralidad en el proceso político, estos actores han sido casi invisibles como objeto de estudio para la academia.

13 Dependiendo del tamaño del partido del presidente aquella porción podría llegar incluso al 50\% del gabinete (Altman 2000). 


\section{CONTEXTO POLÍTICO: DE LA TRANSICIÓN A LA POSTRANSICIÓN}

Durante los cuatro gobiernos de la Concertación (Patricio Aylwin, 19901994, Eduardo Frei, 1994-2000, Ricardo Lagos, 2000-2006, y Michelle Bachelet, 2006-2010), Chile finalizó su transición e inició un proceso de consolidación democrática. Si bien existe un importante debate sobre el momento exacto en que finalizó la transición chilena, este trabajo se ajusta al argumento de Siavelis (2009), quien asume que la transición se extendió desde 1988, año del plebiscito en que Pinochet fue derrotado, hasta el 2005, año en que se reformó la Constitución. Por lo tanto, los primeros gobiernos de la Concertación estuvieron marcados por un contexto político transicional, en el cual las fuerzas armadas mantenían una capacidad de veto relevante sobre el gobierno. La amenaza constante que esto significaba para la estabilidad del sistema político forzó a la Concertación a mantener una política de consensos y diálogo con la derecha y diversos grupos de presión como el empresariado.

La reconstrucción del campo político en el Chile postautoritario fue dominada por una serie de arreglos constitucionales realizados en el marco del proceso de transición. En este contexto, es relevante considerar la existencia de enclaves autoritarios que condicionaron el funcionamiento del sistema político y una arquitectura institucional con implicancias simbólicas y socioculturales que afectaron la recomposición de la élite política chilena (Garretón 1999). Como consecuencia del tipo de transición aquellos enclaves determinaron el quehacer gubernamental por bastante tiempo, casi dos décadas. No obstante las limitantes, el aparato público fue colonizado por militantes y simpatizantes de la Concertación (Delamaza 2011). Es más, lo anterior se dio en el contexto del uso de sistemas de patronazgo y mecanismos informales como el cuoteo que permitieron la recolonización de la administración pública, la cual había sido cuoteada con absoluta discrecionalidad por los militares durante la dictadura (Rehren 2002).

También es importante notar la influencia de los centros de pensamiento o think tanks de la Concertación como vías o senderos para acceder a las posiciones más relevantes en el aparato gubernamental (GonzálezBustamante 2013b, Olivares et al. 2014). Esto permite especular sobre la profundidad que tuvo el proceso de recolonización de la administración pública por parte de la Concertación, pues la evidencia indica que los partidos de la coalición utilizaron sus centros de pensamiento como plataforma de reclutamiento y formación política, siendo utilizados por los militantes para llegar a posiciones de privilegio en el aparato gubernamental 
y como un proxy de credenciales académicas: aquellos militantes no necesariamente poseían capital cultural institucionalizado relevante, pero su participación en los think tanks les permitía subsidiar aquello.

La recolonización fue posible en parte por la existencia de una red de agentes políticos con una orientación socialdemócrata y con credenciales académicas relevantes. Aquellos agentes durante la dictadura trabajaron en think tanks independientes. Esta red operó en términos intelectuales como un contrapunto a la influencia generada por los Chicago Boys durante el régimen militar (Ramos y Scrollini 2013). Aquella red se relaciona con lo que Silva (2011) identifica como élite tecnocrática, la cual lideró la discusión política durante los gobiernos de la Concertación. Se trata de un grupo compuesto por agentes con importantes credenciales académicas obtenidas principalmente en universidades estadounidenses. Este grupo sostuvo fuertes pugnas con la clase política tradicional ${ }^{14}$.

En este contexto, los partidos de la Concertación reconocieron que existía una autoridad suprapartidista ante la cual subordinaron sus intereses y opiniones (Boeninger 1997). Esto tiene relación con el grado de entendimiento, camaradería y consenso que alcanzaron los equipos técnico-políticos durante el mandato de Patricio Aylwin. A esto se suma que la Concertación dejó la política económica en manos de los economistas con perfiles tecnocráticos para demostrar estabilidad y dar una señal de garantía a los empresarios, al Ejército y a la derecha política (Silva 2010). La distribución de ministerios entre los partidos de la Concertación fue un elemento clave para el funcionamiento y la estabilidad gubernamental (Siavelis 2013). Evidentemente se podría suponer que lo mismo aplicaba a nivel de subsecretarías.

En los procesos de conformación de gabinetes operaron mecanismos informales como el cuoteo y la integración vertical. Para Siavelis (2009) el cuoteo fue una elaborada e informal forma de distribución de poder que

14 La pugna entre hombres de partido y tecnócratas fue escalando con el tiempo. Durante el gobierno de Frei surgió la pugna entre autoflagelantes, sector crítico que rechazaba las políticas promercado, y los autocomplacientes, sector que avalaba los resultados obtenidos. Para más detalles véase Silva (2010) y Navia (2004). El conflicto se desreguló alcanzando su punto más alto con la expulsión del senador democratacristiano Adolfo Zaldívar en diciembre de 2007. Zaldívar era un abierto opositor a las políticas tecnocráticas del gobierno y a las configuraciones suprapartidistas (Silva 2010). En este contexto, Michelle Bachelet debió realizar concesiones a los políticos tradicionales debilitando su alianza con sectores tecnocráticos-plasmada en el protagonismo que tuvieron agentes ligados al think tank Espansiva, especialmente Andrés Velasco, ministro de Hacienda de Bachelet-. 
en lo medular consistía en una meticulosa división ministerios entre todos los partidos de la coalición, donde cada uno recibía una cuota según su tamaño e importancia. Esto se complementó con que los subsecretarios fuesen de un partido distinto al del ministro, lo que obedece a una lógica de integración vertical (Rehren 1992). Con esto se buscó promover la capacidad de negociación y la generación de consensos entre los partidos de la coalición, esto como consecuencia del necesario diálogo que el ministro y subsecretario debían desarrollan para, entre otras cosas, nombrar individuos en los diversos cargos de confianza en el Estado.

La influencia del cuoteo y el patronazgo en el proceso de recomposición de la élite política chilena y la recolonización de la administración pública, se dan en el marco de la alta estabilidad del sistema político chileno postautoritario, en el cual de forma inédita para la historia política chilena una coalición gobernó durante 20 años de forma ininterrumpida. Las lógicas informales de distribución de poder en los distintos niveles gubernamentales contribuyeron con dicha estabilidad, pero también dieron paso a un creciente malestar con la concentración de poder por parte de determinados grupos. Existe diversa evidencia sobre la tecnificación que vivió la Concertación. Por ejemplo, Joignant (2011b, 2011c) identifica un grupo de technopols y sugiere la existencia de un círculo íntimo de la coalición compuesto por una veintena de actores que ejercieron un liderazgo transversal y ocuparon las posiciones más relevantes en el campo político. Esto es similar a lo indicado por Ramos y Scrollini (2013) y Silva (2010, 2011).

Los mayores problemas durante los gobiernos de la Concertación se relacionan con ciertos eventos críticos o shocks que afectaron al sistema político. Destaca la influencia de las crisis económicas, particularmente la crisis asiática (1998) y la crisis de las hipotecas subprime (2008). Es importante destacar que Chile estuvo particularmente expuesto a la crisis asiática ya que el $32 \%$ de sus exportaciones se destinaban a países de aquel continente (Esquivel y Larraín 1999). Por otra parte, durante el segundo decenio de los gobiernos concertacionistas salieron a la luz pública diversos casos de corrupción ${ }^{15}$ que impulsaron un creciente malestar ciudadano que coincidió con la irrupción de movimientos sociales que criticaron las políticas impulsadas por la Concertación. Los vínculos entre los movimientos sociales y la política, que en su momento sirvieron para recolonizar la administración pública pinochetista, comenzaron a erosionarse y se generó una distancia entre los políticos instalados en el

15 Varios de estos casos son utilizados en los modelos estadísticos de este artículo, por lo cual se enumeran los más relevantes en el apartado metodológico. 
gobierno y las organizaciones sociales, proceso al que Somma y Bargsted (2015) llaman autonomización de la protesta. En este contexto, emergieron movilizaciones estudiantiles en 2006 y $2008^{16}$, las que se proyectaron con mayor intensidad el ańo 2011 y 2012 bajo la consigna "Fin al lucro en la Educación”, lo que implicó una fuerte demanda social por reformas en el sistema educacional ${ }^{17}$.

A pesar de los eventos críticos durante las dos décadas de gobiernos concertacionistas existió una baja rotación en los gabinetes, lo que se tiende a relacionar con los mecanismos de nombramientos con base en el peso relativo de los partidos de la coalición (Altman 2008, GonzálezBustamante y Olivares 2015, Olivares y González-Bustamante 2015). Es relevante verificar si sucede lo mismo a nivel de subsecretarías: si cuando se realizaba un ajuste ministerial, por las lógicas del cuoteo e integración vertical, también se realizaba un ajuste en las subsecretarías.

Los mecanismos de distribución de poder informales de la Concertación se replicaron, con algunos matices, durante el gobierno de Sebastián Piñera (2010-2014). El triunfo de Piñera en las elecciones presidenciales de 20092010 significó el retorno democrático de la derecha al poder luego de 50 años. El principal desafío del gobierno fue asegurar la gobernabilidad, expresada principalmente en la capacidad de mantener el rumbo del país en materias económicas y en el plano político.

Pese a no enfrentar directamente escándalos de corrupción -aunque si cuestionamientos por conflictos de interés ${ }^{18}-$ ni problemas económicos, uno

$\overline{16}$ Entre el 2006 y 2008 los estudiantes secundarios se movilizaron mediante tomas de colegios, marchas y otras acciones. La movilización inicialmente fue por la gratuidad en la Prueba de Selección Universitaria (PSU) y por un pase de transporte público gratuito y nacional. En la medida que la acción colectiva resultó efectiva y las protestas se fueron masificando, el movimiento amplió sus demandas solicitando reformas en el sistema educacional. Durante el período fueron removidos ministros y la popularidad del gobierno cayó en las encuestas de opinión.

17 Esta demanda social se funda en la premisa de que el sistema educacional no debiese funcionar bajo lógicas de mercado (mercado ficticio). El sistema educacional actual en Chile fue instaurado con las reformas estructurales de corte neoliberal en la década de 1980 en pleno régimen autoritario, aquellas reformas implicaron la privatización de mercados y la extensión de la lógica de mercado a campos no convencionales (Solimano 2014).

18 Por ejemplo, en junio de 2015 el ministro de Segpres, Jorge Insunza, se vio obligado a renunciar a su cargo por denuncias relacionadas con la recepción de honorarios 
de los principales escollos a los que debió hacer frente el gobierno de Piñera fue el aumento y diversificación de la protesta social. Durante este período se desarrollaron las manifestaciones más relevantes de la historia reciente del país (Tricot 2012). Emergieron, por ejemplo, temas relacionados con la distribución de la riqueza entre las regiones ${ }^{19}$, la cuestión educacional mantuvo a universidades públicas y colegios paralizados durante meses, se radicalizó el movimiento mapuche ${ }^{20}$, entre otras cosas. El gobierno tuvo poca capacidad para dialogar con los movimientos sociales, lo que se vincula a las estrategias de conformación de gabinetes que implicaron privilegiar nombramientos de independientes, quienes no mostraron capacidad para enfrentar los problemas políticos y sociales que atravesaba el país.

En resumen, el acceso y la permanencia en el gabinete, tanto a nivel ministerial como en las subsecretarías, tiene relación con la forma en que cada gobierno distribuye el poder mediante mecanismos informales, pero también con las crisis o eventos críticos que enfrenta. A continuación se desarrolla una propuesta analítica para examinar el impacto de estos factores en los subsecretarios.

\section{MÉTODO}

En este artículo se analizan los factores que inciden en la supervivencia de los subsecretarios en Chile durante los gobiernos de la Concertación y el gobierno de Sebastián Piñera. Para esto se evalúan variables institucionales

de compañías mineras mientras presidió el comité de minería cuando fue diputado (Gramacho 2015). Si bien esto no estalló como un escándalo de corrupción relevante, si fue considerado un conflicto de interés, de la misma forma la prensa y la opinión pública especuló bastante sobre los conflictos de interés del presidente Piñera y de varios de sus ministros debido a sus vínculos e intereses empresariales.

19 Las protestas en Magallanes contra el alza del gas en enero de 2011 fueron la primera señal de la molestia de esa región con las políticas del gobierno, particularmente con el alza en las tarifas del gas natural en la región. Las movilizaciones tuvieron como consecuencia la salida del gabinete del ministro de Energía. Un año después, en febrero de 2012, la región de Aysén se movilizó para hacer ver al gobierno su situación. Estas movilizaciones recibieron alto apoyo en todo el país y se realizaron protestas en diferentes regiones y en la capital.

20 Una huelga de hambre de comuneros mapuche que se encontraban en prisión preventiva provocó una serie de movilizaciones entre los estudiantes universitarios de diversas zonas del país entre julio y octubre de 2010. Junto con ello se desarrollaron marchas y protestas que complicaron al gobierno, el cual finalmente decidió tomar parte de una mesa de diálogo con la Iglesia Católica y los comuneros. 
y eventos críticos (shocks) como predictores de supervivencia/riesgo. Se sostienen las siguientes hipótesis:

$\mathrm{H}_{1}$ : Los factores institucionales, específicamente la integración vertical entre ministerio y subsecretaría y la dependencia de un ministerio no político, constituyen predictores de supervivencia en las subsecretarías durante los gobiernos chilenos entre 1990 y 2014.

$\mathrm{H}_{2}$ : Los eventos críticos o shocks, específicamente las crisis económicas, baja aprobación presidencial, casos de corrupción y alta movilización social, constituyen factores de riesgo para la supervivencia en las subsecretarías durante los gobiernos chilenos entre 1990 y 2014.

$\mathrm{H}_{3}$ : Las rotaciones ministeriales relevantes condicionan la supervivencia en las subsecretarías durante los gobiernos chilenos entre 1990 y 2014.

En esta investigación se trabaja con estadística multivariante, específicamente con modelos de interdependencia y dependencia. En los modelos de interdependencia se utiliza análisis de clúster que permite mediante un algoritmo de agrupamiento clasificar a los individuos en grupos homogéneos internamente pero heterogéneos con respecto al resto de la muestra. El algoritmo que se utiliza corresponde a un agrupamiento no jerárquico, particularmente $K$-means clustering, que optimiza el número de particiones entre los subsecretarios en cada gobierno con base en las siguientes variables: 1) sobrevivencia en la subsecretaría; 2) sexo; 3) militancia; y 4) integración vertical. Para esto se trabaja con el criterio/ índice (stopping-rule) Calińiski-Harabasz con base en el F ratio de ANOVA ( seudo- $F$ index ${ }^{21}$ ), lo que permite calcular la distancia euclidiana con el método de transformación Hellinger (Oksanen 2014). De esta forma se obtienen gráficos Mondorian que permiten visualizar la conformación de particiones por período ${ }^{22}$.

Para los modelos de dependencia se trabaja con análisis de regresiones. Específicamente se trabaja con análisis de supervivencia que resulta pertinente para evaluar la permanencia de los individuos en sus cargos y ha

21 De Acuerdo a Milligan y Cooper (1985) los mejores pseudo-F como stopping-rules para número clúster son Caliński-Harabasz y Duda-Hart.

22 Estos gráficos son similares a los gráficos Marimekko o de mosaico. Se llaman Mondorian en honor a Pieter Cornelis Mondriaan, más conocido como Piet Mondorian, pintor vanguardista de principios del siglo XX (Países Bajos, 1872 Estados Unidos, 1944). 
sido utilizado en diversos trabajos recientes sobre gabinetes (e.g., Camerlo y Pérez-Liñán 2015, Kerby 2015, Martínez-Gallardo 2014, Quiroz 2015). Para esto se siguen las técnicas de Hosmer, Lemeshow y May (2008), que permiten estimar la supervivencia de los subsecretarios con curvas KaplanMeier y analizar los predictores con modelos de riesgos proporcionales o regresiones de Cox (1972, 1975). Se utilizan específicamente regresiones de Cox con fragilidad compartida (Cox shared-frailty model), modelos análogos a las regresiones con efectos aleatorios del análisis multinivel que permiten incluir variables latentes en la modelación como debilidades compartidas de un grupo.

\section{Tabla 1: Detalles técnicos de los modelos de riesgos proporcionales con fragilidad compartida gamma $(\gamma)$}

\begin{tabular}{|c|c|c|}
\hline Ítem & Fuente & Detalle \\
\hline $\begin{array}{l}\text { Método de ajuste para } \\
\text { eventos colindantes }\end{array}$ & Efron (1977) & $\begin{array}{c}\text { Menos usado y requiere de mayor } \\
\text { cálculo que Breslow (1974), pero es } \\
\text { más exacto }\end{array}$ \\
\hline $\begin{array}{l}\text { Eventos por variable } \\
\text { predictor }\end{array}$ & $\begin{array}{c}\text { Vittinghoff y } \\
\text { McCulloch (2006) }\end{array}$ & Diez o más eventos por variable \\
\hline $\begin{array}{l}\text { Suposición de riesgos } \\
\text { proporcionales } \\
\text { (PH Assumption) }\end{array}$ & $\begin{array}{c}\text { Grambsch y } \\
\text { Therneau (1994) }\end{array}$ & Escala de residuos de Schoenfeld \\
\hline $\begin{array}{l}\text { Fragilidad compartida } \\
\qquad \operatorname{gamma}(\gamma)\end{array}$ & $\begin{array}{c}\text { Therneau y } \\
\text { Grambsch (2000) }\end{array}$ & $\begin{array}{c}\text { Ponderación del log likelihood, } \beta_{\mathrm{n}} \mathrm{y} \\
\mathrm{SE}_{\mathrm{n}} \text { por debilidad theta }(\vartheta)\end{array}$ \\
\hline
\end{tabular}

Nota: Además se realizaron análisis bivariados para evitar multicolinealidad. Fuente: Elaboración propia.

Los datos de este artículo son parte de un proyecto de investigación más amplio sobre rotación en los gabinetes en Chile durante los siglos XX y XXI, cuyos avances preliminares se pueden revisar en GonzálezBustamante y Olivares (2015) y Olivares y González-Bustamante (2015). Los resultados definitivos se pueden revisar en este artículo y en próximas publicaciones enfocadas en gabinetes ministeriales. Se utilizan conjuntos de datos construidos con fuentes de acceso público, en este artículo se utilizan datos de los subsecretarios entre 1990 y 2014 (Tabla 2). Con esto se realiza un análisis de supervivencia con datos censurados de registro único. 
Tabla 2: Cantidad de subsecretarios en Chile (1990-2014)

\begin{tabular}{ccc} 
Gobierno & Período & Subsecretarios \\
\hline Patricio Aylwin & $1990-1994$ & 38 \\
Eduardo Frei & $1994-2000$ & 61 \\
Ricardo Lagos & $2000-2006$ & 72 \\
Michelle Bachelet & $2006-2010$ & 62 \\
Sebastián Piñera & $2010-2014$ & 57 \\
& & 290
\end{tabular}

Nota: El conjunto de datos fue construido con fuentes de acceso público. Cada caso corresponde a nombramientos no a individuos. Fuente: Elaboración propia.

En los modelos de riesgos proporcionales se registra un fracaso cuando un subsecretario fue removido de su cargo con las siguientes excepciones: aquellos individuos que dejaron el cargo para asumir otra subsecretaría o un ministerio ${ }^{23}$ y aquellos que dejaron el cargo durante un año de elecciones para ser candidatos al congreso o asumir un puesto relevante en el comando de campaña presidencial del candidato de la coalición. Aquellos subsecretarios que terminan el mandato con el presidente son calificados como "sobrevivientes" aplicando censura administrativa.

Las variables independientes utilizadas en las regresiones de Cox corresponden a características institucionales y shocks sobre el sistema político: $\left(\mathrm{X}_{1}\right)$ tipo de dependencia ministerial; $\left(\mathrm{X}_{2}\right)$ crisis económicas; $\left(\mathrm{X}_{3}\right)$ baja aprobación presidencial; $\left(\mathrm{X}_{4}\right)$ escándalos de corrupción; y $\left(\mathrm{X}_{5}\right)$ movilización social.

La dependencia ministerial $\left(\mathrm{X}_{1}\right)$ se evalúa con base en la vinculación a un ministerio político, para lo cual se sigue la definición de Joignant (2011b) sobre este tipo de ministerios excluyendo las áreas de defensa y relaciones exteriores por poseer un bajo nivel de rotación: Interior, Hacienda, Segpres y Secretaría General de Gobierno (Segegob).

23 Hay varios individuos que dejaron una subsecretaría para ser embajadores, aquello fue considerado como un fracaso. Si bien ser embajador constituye una posición relevante en el campo político, también implica alejarse del centro de poder presidencial. 
La crisis económicas $\left(\mathrm{X}_{2}\right)$ que fueron consideradas son la crisis asiática (septiembre de 1998 a diciembre de 1999) y la crisis de las hipotecas subprime (octubre de 2008 a diciembre de 2009). Como consecuencia directa de la política de liberalización de la economía y apertura al sector exterior ambas crisis internacionales tuvieron impactos directos en la economía del país. La crisis asiática golpeó con mucha más fuerza que la subprime. Durante la crisis asiática el desempleo se elevó sobre el $10 \%$ por primera vez en quince años, la inflación aumentó de manera significativa, cayó el PIB, entre otros efectos. La crisis subprime desaceleró la economía chilena, sin embargo, el impacto no fue tan profundo, en parte por los aprendizajes que dejó la crisis asiática.

Para la baja aprobación presidencial $\left(\mathrm{X}_{3}\right)$ se consideraron umbrales inferiores al $40 \%$ en la encuesta del Centro de Estudios Públicos (CEP), esto porque aquella cifra se encuentra bajo el primer cuartil de la aprobación durante el período del estudio ${ }^{24}$.

Los escándalos de corrupción $\left(\mathrm{X}_{4}\right)$ se resumen en los siguientes casos que tuvieron gran impacto político y mediático entre 1990 y 2014: 1) Casas Copeva (junio a julio de 199725); 2) Coimas, MOP-Gate, MOP-Ciade, MOP-Idecon y Corfo Inverlink (enero de 2002 a diciembre de 201326); y

24 Se utiliza la respuesta a la siguiente pregunta: Independiente de su posición política, ¿usted aprueba o desaprueba la forma como está conduciendo el presidente el gobierno?

25 La constructora de viviendas sociales Copeva edificó un conjunto de casas que presentaron fallas estructurales durante el invierno de 1997. El proceso de investigación determinó que la empresa había realizado regalos a altos personeros políticos con el fin de ganar la licitación de las obras.

26 En el caso Coimas varios diputados recibieron dinero para gestionar en el Ministerio de Transportes el permiso para una planta de revisión técnica. Fueron procesados cinco diputados y el dueño de las plantas de revisión. Los casos que involucran al Ministerio de Obras Públicas (MOP) y la empresa de Gestión Ambiental y Territorial (Gate), Centro de Investigaciones Aplicadas para el Desarrollo de la Empresa (Ciade) y el Instituto de Economía (Idecon), fueron triangulaciones de dinero para pagar sobresueldos a funcionarios del ministerio, además, en varios casos, los servicios pagados no fueron realizados. El caso entre la Corporación de Fomento de la Producción (Corfo) e Inverlink es un traspaso ilegal de activos desde la primera (empresa estatal) a la segunda (empresa privada), también se incluye una arista en la cual Inverlink pagó a la secretaria del presidente del Banco Central por acceso a información reservada y así realizar un análisis de impacto de estos casos en la administración pública, para más detalles véase Olavarría (2011). 
3) Chiledeportes (diciembre de 2005 a octubre de $2006^{27}$ ).

Finalmente, para movilización social $\left(\mathrm{X}_{5}\right)$ se consideran los períodos que concuerdan con los siguientes casos: 1) movilizaciones secundarias (septiembre a octubre de 2006 y mayo a junio de 2008); 2) huelga de hambre de comuneros mapuche que implicó movilizaciones estudiantiles de apoyo (julio a octubre de 2010); 3) protestas medioambientales de Barrancones (agosto de 201028); 4) protestas regionales en Magallanes (enero de 2011) y Aysén (febrero a marzo de 2012); y 5) movilizaciones estudiantiles (abril a diciembre de 2011 y marzo a agosto de $2012^{29}$ ).

La variable $\mathrm{X}_{1}$ es una variable dicotómica binaria. Las variables $\mathrm{X}_{2}$, $\mathrm{X}_{3}, \mathrm{X}_{4} \mathrm{y} \mathrm{X}_{5}$ se calculan con base en los días expuestos al shock ponderados por el tiempo que el individuo ejerció como subsecretario, esto genera variables numéricas que van de cero a 100 . Es importante tener esto en cuenta para interpretar los efectos de las variables significativas en la modelación estadística, ya que en los modelos de riesgos proporcionales, al igual que en los modelos lineales (ordinary least squares), hay que considerar los efectos de las variables numéricas significativas basándose en cada unidad de la variable independiente.

Como se trabaja con regresiones de Cox con fragilidad compartida gamma, se condiciona y pondera el log likelihood de la modelación, los coeficientes $\beta$ y los errores estándar a una debilidad theta $(\vartheta)$ que opera como variable latente. En esta investigación se trata de las rotaciones

27 Escándalo derivado de la asignación de recursos fiscales a empresas ficticias, personas muertas o funcionarios del organismo estatal. Uno de los fondos utilizados, el Fondo Nacional de Deporte, podía ser asignado de manera directa por el jefe de servicio que tenía rango de subsecretario. En la medida que avanzó la investigación diversos políticos de los partidos de la Concertación fueron depuestos de sus cargos.

28 Ante la decisión de construir la central termoeléctrica Barrancones en sector Punta de Choros, Isla Damas e Isla Gaviota, se provocaron una serie de movilizaciones multitudinarias en diferentes ciudades de Chile para oponerse al proyecto. Estas movilizaciones generaron una presión relevante sobre el sistema político que significó la intervención extrainstitucional del presidente para que la central no fuese construida en dicha zona.

29 La movilización estudiantil del año 2011 corresponde a una serie de manifestaciones nacionales donde participaron universitarios y secundarios bajo la consigna "Fin al lucro en la Educación”. Estas han sido las movilizaciones más importantes en términos de alcance y masificación desde el retorno a la democracia en Chile. Para más detalles sobre los eventos de protesta y su magnitud véase Cummings (2015). 
ministeriales relevantes. Esta variable latente fue operacionalizada con base en todos los ajustes ministeriales realizados durante los 24 ańos del período estudiado considerando un criterio de inclusión: aquellos cambios que implicaron más del $25 \%$ de rotación del gabinete ${ }^{30}$. Para la rotación se contabilizaron todos los cambios de ministros en cada ajuste, ponderando las caretas políticas por dos. Además se consideraron como un solo ajuste aquellos que se realizaron con una semana de diferencia como máximo. Esto permitió identificar las siguientes rotaciones ministeriales relevantes: 1) cuatro eventos durante el gobierno de Frei; 2) tres eventos durante el gobierno de Lagos; 3) dos eventos durante el gobierno de Bachelet; y 4) dos eventos durante el gobierno de Piñera. Todos los subsecretarios que ejercieron su cargo durante aquellos períodos, específicamente durante un mes desde que ocurrió el evento de alta rotación ministerial, fueron considerados como expuestos a la debilidad o fragilidad compartida.

Por último, se revisa la bondad de ajuste (goodness of fit) de los modelos con un análisis de la pendiente de los residuos Cox-Snell comparado con la función de riesgo acumulada Nelson-Aalen (Hosmer et al. 2008). También se utiliza una medición de bondad de ajuste alternativa para los modelos de riesgos proporcionales. Royston y Sauerbrei (2004) propusieron la medida $D$ para evaluar un modelo de sobrevivencia, de forma similar O'Quigley, Xu y Stare (2005) propusieron usar una versión modificada de Nagelkerke $R^{2}$ para los modelos de Cox llamada $p_{-} k^{\wedge} 2$. En este artículo se trabaja con $R \_D^{\wedge} 2$ que es una transformación de $D$ a través de la ordenación de los coeficientes $\mathrm{x} \beta$ calculando la distribución normal esperada y ponderando por un factor $\mathrm{k}=\sqrt{ }(8 / \pi)$ para luego ajustar la medición con regresiones auxiliares sobre los coeficientes ponderados (Royston 2006).

\section{RESULTADOS}

De los 290 subsecretarios que ejercieron entre 1990 y 2014 en Chile, la gran mayoría fueron hombres: el 76,2\% $(n=221)$. Los gobiernos que presentan mayor cantidad de mujeres en las subsecretarías son el de Bachelet y de Piñera, en cambio, la peor tasa le corresponde al gobierno de Frei: Aylwin $=10,5 \%$; Frei $=9,8 \%$; Lagos $=25 \%$; Bachelet $=38,7 \%$; Piñera $=$ $29,8 \%$. Los datos evidencian una participación creciente de mujeres en las subsecretarías. Por otra parte, un 79\% $(n=229)$ de los subsecretarios tenía una militancia activa en alguno de los partidos de la coalición al momento de ejercer su cargo. Los gobiernos con más independientes fueron el de

30 Para esto se utilizó información de los 232 ministros que ejercieron entre 1990 y 2014 de acuerdo a datos de González-Bustamante y Olivares (2015) y Olivares y GonzálezBustamante (2015). 
Aylwin y de Piñera, el primero dado el contexto político transicional, el segundo por la tradición política de la derecha chilena de privilegiar a figuras independientes en cargos políticos: Aylwin $=21,1 \%$; Frei $=19,7 \%$; Lagos $=4,2 \%$; Bachelet $=11,3 \%$; Piñera $=54,4 \%$.

A continuación se presentan los gráficos Mondorian que permiten comparar las particiones $K$-means de subsecretarios por gobierno (Figura 1). Estos gráficos también ofrecen valores exactos del índice CalińskiHarabasz cuyo valor óptimo es nueve para cada gobierno: Aylwin = 177,776; Frei $=103,057$; Lagos $=96,369 ;$ Bachelet $=85,081 ;$ Piñera $=$ 69,900. Valores bajos implican menos claridad en la estructura de clúster. Al contrario, valores altos indican estructuras bien definitivas. En este contexto, destacan los índices de los gobiernos de Aylwin y Frei que muestran que los subsecretarios en aquellos períodos conformaron grupos más homogéneos y claramente identificables. Sucede absolutamente lo contrario en los gobiernos de Bachelet y de Piñera. Esto evidencia el nivel de cierre/homogeneidad versus el nivel de apertura/heterogeneidad en los subsecretarios como elenco elitario o subelite. 
Figura 1: Gráficos Mondorian para comparación de particiones K-means de subsecretarios en Chile (1990-2014)

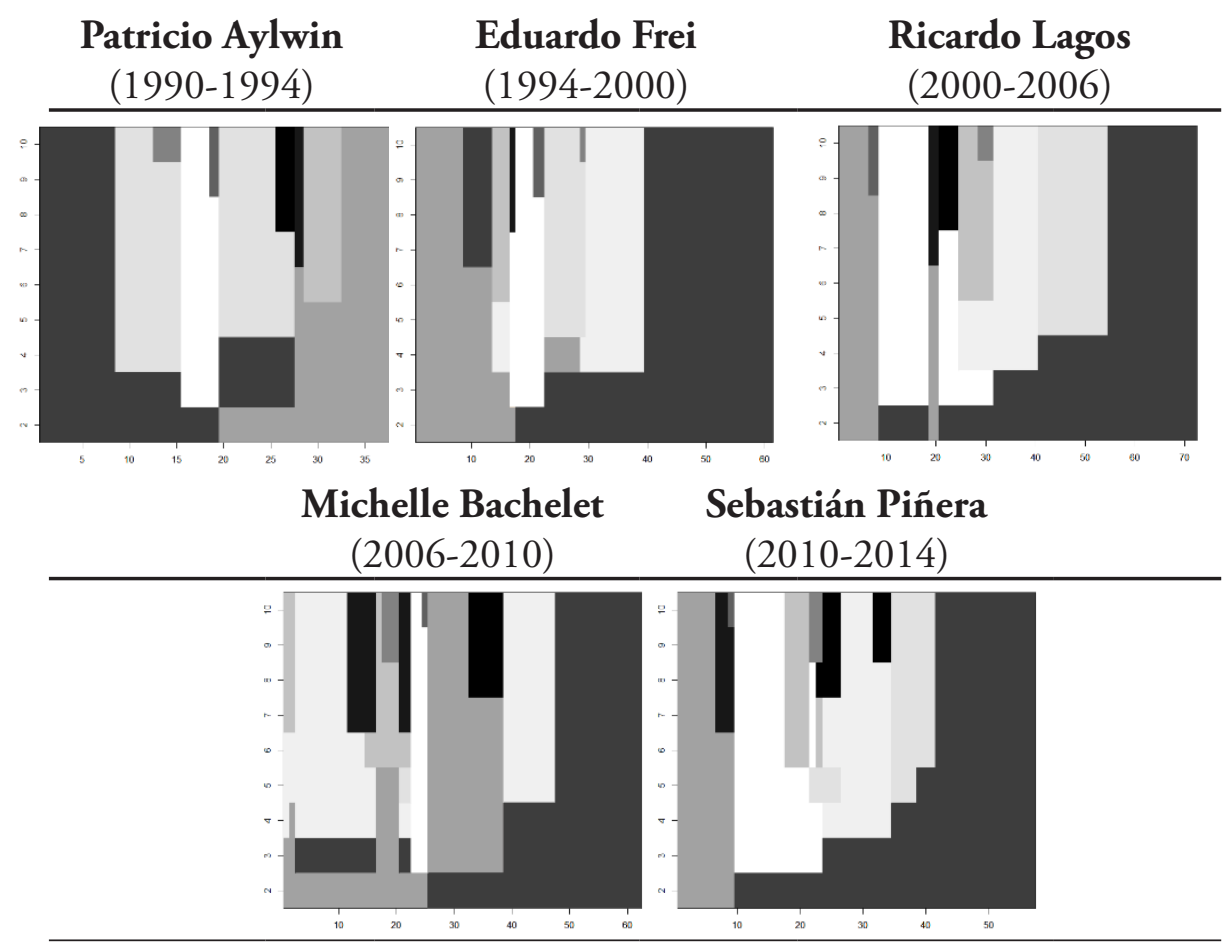

Nota: En el eje X se grafica la cantidad de casos para los periodos analizados y en el eje Y el número de grupos en cada partición. Fuente: Elaboración propia.

Las tasas de incidencia y el nivel de rotación muestran que el gobierno de Patricio Aylwin fue bastante estable a nivel de subsecretarías (Tabla 3). Lo mismo se confirma en análisis preliminares sobre los ministros del período como González-Bustamante y Olivares (2015) y Olivares y González-Bustamante (2015). Los porcentajes de rotación ratifican lo anterior: Aylwin rotó el $25 \%$ de sus subsecretarios después de los dos años de mandato, el resto de los gobiernos lo hizo entre el primer y segundo año de sus mandatos. 


\section{Tabla 3: Riesgo, incidencia y rotación de los subsecretarios en Chile} (1990-2014)

\begin{tabular}{cccccc} 
Gobierno & $\begin{array}{c}\text { Días en } \\
\text { riesgo }\end{array}$ & $\begin{array}{c}\text { Tasa de } \\
\text { incidencia }\end{array}$ & $\mathbf{2 5 \%}$ & $\mathbf{5 0 \%}$ & $\mathbf{7 5 \%}$ \\
\hline Aylwin & 38.997 & 0,0004 & 799 & - & - \\
Frei & 58.874 & 0,0008 & 606 & 1.018 & 1.586 \\
Lagos & 62.192 & 0,0008 & 528 & 838 & 1.516 \\
Bachelet & 43.658 & 0,0009 & 453 & 671 & 1.347 \\
Piñera & 45.525 & 0,0008 & 418 & 953 & - \\
Total & 249.246 & 0,0007 & 490 & 928 & 1.670
\end{tabular}

Nota: Los días en riesgo se calculan con base en la cantidad de subsecretarios de cada gobierno y su tiempo en el cargo. La tasa de incidencia corresponde al número de nuevos casos que dejan el gabinete con base en la población en riesgo por unidad de tiempo. A mayor tasa de incidencia, mayor cese de funciones en las subsecretarias. Fuente: Elaboración propia.

El nivel de rotación se puede apreciar directamente a través de la estimación de supervivencia con curvas Kaplan-Meier (Figura 2). Se presentan estimaciones ajustadas por gobierno que permiten distinguir los efectos de ciertas variables individuales de los subsecretarios: sexo, militancia y existencia de integración vertical entre ministerio y subsecretaría. El análisis con curvas Kaplan-Meier permite apreciar el comportamiento de los coeficientes de riesgo (hazard ratio) por variable: ser mujer constituye un predictor de supervivencia, asimismo desempeñarse en una subsecretaría integrada verticalmente con el ministerio también lo es. Lo que sucede con las mujeres es interesante pues si bien pocas llegan a posiciones relevantes en la élite política, para aquellas que lo logran, su sexo les ayuda a sobrevivir en el cargo, al menos en las subsecretarías. Por otra parte, hacia el final de los mandatos se aprecia una diferencia entre independientes y militantes de partidos de la coalición: ser independiente resulta ser un factor de riesgo, lo cual podría ser consistente con la idea de que aquellos independientes corresponden a la cuota reservada por el presidente para su círculo de confianza en el proceso de conformación de los gabinetes. 
Figura 2: Función de supervivencia por características individuales de los subsecretarios en Chile (1990-2014)

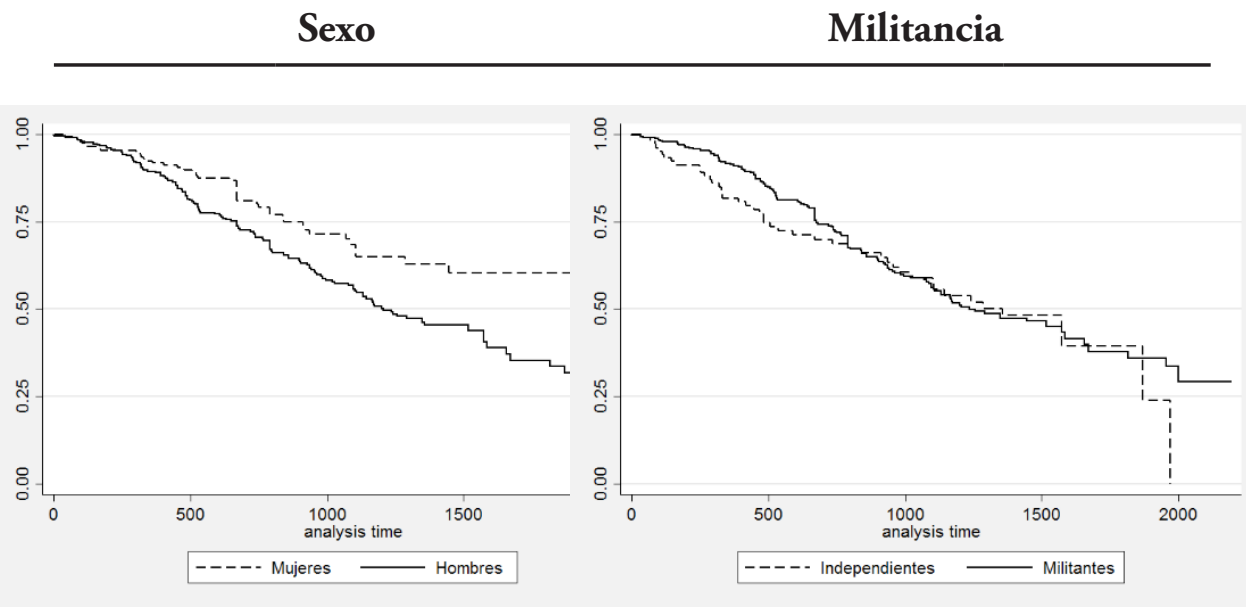

\section{Integración vertical}

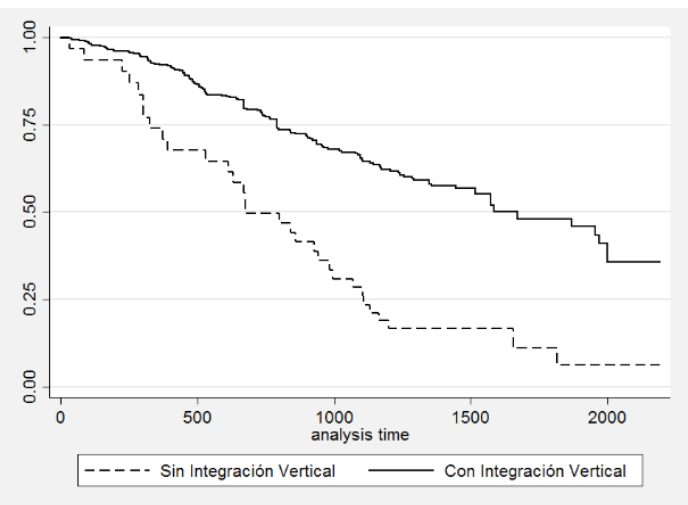

Nota: Las estimaciones Kaplan-Meier fueron ajustadas por gobierno. Fuente: Elaboración propia.

Se realizaron dos modelaciones con regresiones de Cox condicionadas a la fragilidad compartida de rotación ministerial (Tabla 4). La interpretación de los modelos se puede realizar con los coeficientes de riesgo (hazard ratio) considerando que cuando el coeficiente es mayor a uno la variable es un factor de riesgo y cuando es menor a uno es un predictor de supervivencia. Se puede realizar la misma interpretación con los coeficientes $\beta$ pero de forma inversa. El modelo I, correspondiente a los gobiernos de la 
Concertación, muestra que las crisis económicas y los escándalos de corrupción son factores de riesgo estadísticamente significativos para los subsecretarios. Por otra parte, el modelo II, correspondiente al gobierno de Sebastián Pińera, muestra que la alta movilización social es un predictor de supervivencia estadísticamente significativo a nivel de subsecretarías. Ambos modelos se encuentran condicionados significativamente a los eventos de rotación ministerial relevantes.

Los resultados del modelo I sugieren que durante los gobiernos de la Concertación las crisis económicas y los escándalos de corrupción fueron eventos significativos que provocaron que subsecretarios dejaran sus cargos, además los eventos de alta rotación ministerial también resultan relevantes como variable latente. Los resultados del modelo II son llamativos pues la evidencia sugiere que durante el gobierno de Sebastián Piñera la movilización social en lugar de ejercer presión sobre el sistema político generaba todo lo contrario, tanto así que aquella variable constituye un predictor de supervivencia para los subsecretarios.

Es relevante considerar que puede parecer que los efectos de las variables significativas son marginales dado los valores de los coeficientes en los modelos, sin embargo, las variables independientes fueron calculadas con base en los días expuestos al shock ponderados por el período que cada individuo ejerció como subsecretario, por lo cual se debe considerar que el efecto se calcula por cada unidad de la variable independiente. Esto hace que la magnitud de los efectos sea bastante relevante.

Por último, la bondad de ajuste se mide con la comparación de los residuos Cox-Snell y la función de riesgo acumulada Nelson-Aalen (Figura 3). Se puede apreciar que el ajuste del modelo II es mejor, pues si bien existe un desajuste (some wiggling), éste es en la cola donde la variabilidad de la estimación de la incertidumbre es mayor (Box-Steffensmeier y Jones 2004). Al calcular $R \_D^{\wedge} 2$ con $\mathrm{CI}_{95 \%}$ se obtienen los valores 0,294 y 0,383 en los intervalos superiores para los modelos I y II respectivamente. 


\section{Tabla 4: Regresiones de Cox con método Efron y fragilidad compartida gamma $(\gamma)$ para supervivencia de subsecretarios en Chile (1990-2014)}

\begin{tabular}{|c|c|c|}
\hline Variables & $\begin{array}{c}\text { Modelo I } \\
(1990-2010)\end{array}$ & $\begin{array}{c}\text { Modelo II } \\
(2010-2014)\end{array}$ \\
\hline \multirow{3}{*}{ Integración vertical } & 0,765 & 1,895 \\
\hline & $(-0,268)$ & $(0,639)$ \\
\hline & $(0,217)$ & $(0,623)$ \\
\hline \multirow{3}{*}{ Ministerio político } & 0,964 & 0,391 \\
\hline & $(-0,036)$ & $(-0,940)$ \\
\hline & $(0,206)$ & $(0,622)$ \\
\hline \multirow{4}{*}{ Crisis económicas } & $1,019^{* * *}$ & \\
\hline & $(0,019)$ & -- \\
\hline & $(0,005)$ & \\
\hline & 1,003 & \\
\hline \multirow[t]{2}{*}{ Baja aprobación presidencial } & $(0,003)$ & - \\
\hline & $\begin{array}{c}(0,004) \\
1,023^{* * *}\end{array}$ & \\
\hline \multirow[t]{3}{*}{ Casos de corrupción } & $(0,023)$ & - \\
\hline & $(0,005)$ & \\
\hline & 1,002 & $0,982^{* *}$ \\
\hline \multirow[t]{2}{*}{ Movilización social } & $(0,002)$ & $(-0,018)$ \\
\hline & $(0,027)$ & $(0,008)$ \\
\hline Shared-frailty & Rot. Ministerial & Rot. Ministerial \\
\hline theta $(\vartheta)$ & $\begin{array}{c}0,271^{* * *} \\
(0,288)\end{array}$ & $\begin{array}{c}1,905^{* * *} \\
(1,704)\end{array}$ \\
\hline Likelihood-radio test theta $(\vartheta)$ & 0,000 & 0,000 \\
\hline Observaciones & 233 & 57 \\
\hline Prob $>X^{2}$ & 0,000 & 0,048 \\
\hline Log likelihood & $-693,529$ & $-101,975$ \\
\hline PH Assumption & 0,145 & 0,546 \\
\hline Días en riesgo & 203.721 & 45.525 \\
\hline
\end{tabular}

Nota: Se indica hazard ratio, coeficientes $\beta$ y errores estándar entre paréntesis. Todos los coeficientes y errores se encuentran condicionados a theta $(\vartheta)$. Significancia: ${ }^{* *} p<0,01,{ }^{* *} p<0,05,{ }^{*} p<0,1$. Fuente: Elaboración propia 
Figura 3: Bondad de ajuste de los modelos de regresión para la supervivencia de subsecretarios en Chile (1990-2014)

Modelo I

(1990-2010)
Modelo II

(2010-2014)
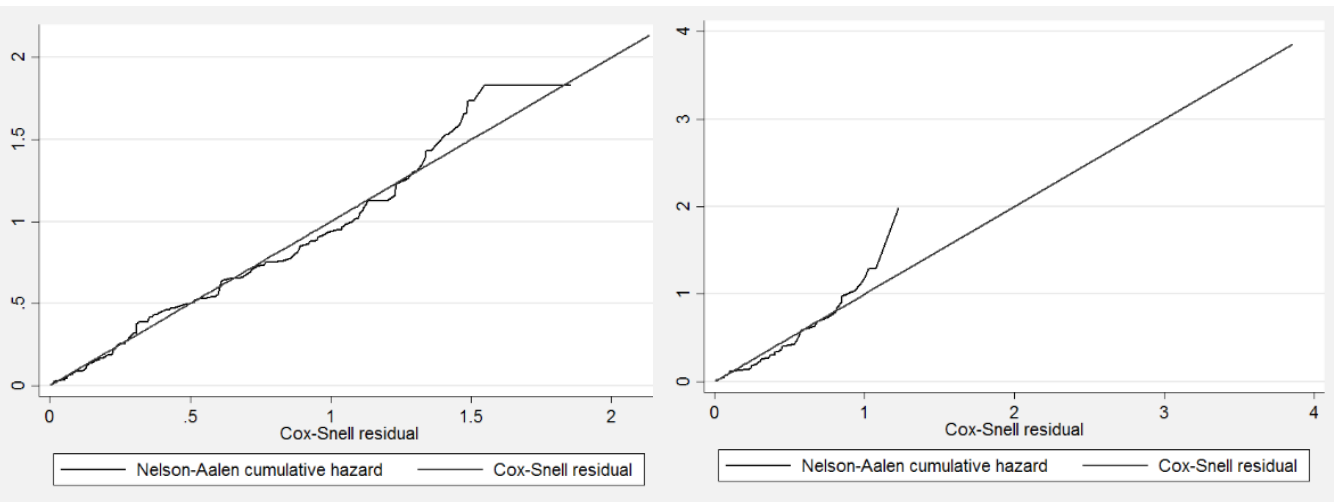

Nota: Se grafica función de riesgo acumulada Nelson-Aalen y residuos Cox-

Snell.

Fuente: Elaboración propia.

\section{CONCLUSIONES}

Los resultados de los modelos con regresiones de Cox con método Efron y fragilidad compartida gamma permiten analizar las hipótesis de trabajo propuestas inicialmente. La primera hipótesis que indica que la integración vertical entre subsecretaría y ministerio y la dependencia de una cartera no política constituyen predictores de supervivencia se rechaza. En ninguno de los dos modelos aquellas variables resultan estadísticamente significativas.

La segunda hipótesis, relacionada con que los shocks como las crisis económicas, baja aprobación presidencial, casos de corrupción y movilización social constituyen factores de riesgo para la supervivencia en las subsecretarías, se comprueba parcialmente. Solo resultan estadísticamente significativas las crisis económicas, los casos de corrupción y la movilización social, con efectos distintos y en períodos diferentes. Las crisis económicas y los escándalos de corrupción afectaron particularmente a los gobiernos de la Concertación generando mayor riesgo en las subsecretarías, por otra parte, la movilización social resultó significativa en el gobierno de Piñera con un efecto inverso, es decir, como un predictor de supervivencia. Este último resultado es interesante, pues sugiere que en aquel gobierno la 
movilización social en lugar de ejercer presión sobre el sistema político generaba un cierre e inmovilidad, al menos a nivel de subsecretarías.

Por último, la tercera hipótesis, relacionada con que las rotaciones ministeriales relevantes condicionan la supervivencia en las subsecretarías para el período estudiado, se comprueba. Los modelos estadísticos muestran que las rotaciones ministeriales operan como variable latente estadísticamente significativa que funciona como debilidad o fragilidad compartida para los subsecretarios que estuvieron expuestos a períodos de ajustes. Esto implica que la rotación ministerial tiene una influencia en la supervivencia de los subsecretarios.

De forma complementaria, los análisis de clúster, las tasas de rotación e incidencia y las estimaciones Kaplan-Meier ofrecen un panorama bastante preciso sobre la rotación en las subsecretarías chilenas entre 1990 y 2014. Lo que se debiese profundizar son temas relacionados con las características individuales de los subsecretarios en una lógica de recursos y capitales, donde la teoría sociológica de Pierre Bourdieu ofrece un marco bastante útil para apreciar cómo características personales permiten acceder y desarrollar carreras políticas (Garrido 2013, Joignant 2011a). Por otra parte, una cuestión importante que no fue abordada en este artículo es el nivel de proporcionalidad que existe en los nombramientos a nivel de subsecretarías con respecto al peso relativo de los partidos de la coalición en el congreso. Trabajos como Avendaño y Dávila (2012) ofrecen cálculos de proporcionalidad basándose en el respaldo electoral y la participación de los partidos en los gabinetes concertacionistas. Sin embargo, aunque la reflexión va en la dirección correcta, aquel cálculo no resulta del todo adecuado ya que no considera el dinamismo dentro de los gabinetes con base en la rotación y supervivencia, el calendario electoral y además el efecto de la desproporcionalidad (malapportionment) sobre el proceso de conformación del gabinete (véase Bhavnani 2015). En definitiva, aquel tema debe ser abordado en otro artículo y de forma más precisa.

Los hallazgos de este artículo resultan relevantes en dos dimensiones. Primero, son un aporte original y pionero con respecto al estudio de los subsecretarios como segunda línea gubernamental. Como se advierte en el desarrollo de los distintos apartados de este trabajo, particularmente en el apartado teórico, la academia no le ha prestado mayor atención a este nivel de la carrera política. Segundo, a pesar de que ésta es una primera aproximación con pretensiones exploratorias, se ofrece un panorama bastante exacto sobre la rotación de los subsecretarios y los factores que afectan su supervivencia en un período bastante considerable. Estos hallazgos resultan relevantes para aquellos que estudian las élites 
políticas, sin embargo, también son importantes para los interesados en el funcionamiento de la administración pública, esto porque el nivel rotación de los subsecretarios impacta en la calidad de la gestión; en aquellas áreas donde el nivel es alto probablemente existen problemas de gestión, las áreas más estables, en cambio, debiesen funcionar mejor. En este sentido, se advierten dos posibles líneas de investigación: evaluar que sucede en los niveles jerárquicos inferiores y estudiar el impacto de una elevada tasa de rotación en la gestión y administración de áreas gubernamentales específicas. 


\section{REFERENCIAS}

Alcántara, M. (2012). El Oficio de Político. Madrid: Tecnos. . (2013). De Políticos y Política: Profesionalización y Calidad del Ejercicio Público. Perfiles Latinoamericanos, 41, 19-44.

Alcántara, M. y Luna, J. P. (2004). Ideología y Competencia Partidaria en dos Post-transiciones: Chile y Uruguay en Perspectiva Comparada. Revista de Ciencia Política, 24 (1), 128-168.

Altman, D. (2000). The Politics of Coalition Formation and Survival Multiparty Presidential Democracies: The case of Uruguay, 19891999. Party Politics, 6 (3), 259-283.

. (2008). Political Recruitment and Candidate Selection in Chile, 1990 to 2006: The Executive Branch. En Siavelis, P. M. y Morgenstern, S. (Eds.), Pathways to Power: Political Recruitment and Candidate Selection in Latin America. University Park: Penn State University Press.

Amorim Neto, O. (2000). Gabinetes Presidenciais, Ciclos Eleitorais e Disciplina Legislativa no Brasil. Dados, Revista de Ciências Sociais, 43 (3), 479-519.

Avendaño, O. y Dávila, M. (2012). Rotación Ministerial y Estabilidad Coalicional en Chile, 1990-2010. Politica, Revista de Ciencia Política, 50 (2), 87-108.

Batista, M. (2013). O Poder no Executivo: Uma Análise do Papel da Presidência e dos Ministérios no Presidencialismo de Coalizão Brasileiro (1995-2010). Opinião Pública, 19 (2), 449-473.

Best, H. (2011). The Elite-Population Gap in the Formation of Political Identities. A Cross-Cultural Investigation. Europe-Asia Studies, 63 (6), 995-1009.

Bhavnani, R. R. (2015). The Effects of Malapportionment on Cabinet Inclusion: Subnational Evidence from India. British Journal of Political Science. doi: 10.1017/S0007123415000587

Birle, P., Hofmeister, W., Malhold, G. y Potthast, B. (2007). Elites en América Latina. Madrid: Iberoamericana-Vervuert. 
Blondel, J. (1988). Ministerial Careers and the Nature of Parliamentary Government: The Cases of Austria and Belgium. European Journal of Political Research, 16 (1), 51-71.

Blondel, J. y Müller-Rommel, F. (1993). Governing Together: The Extent and Limits of Joint Decision-Making in Western European Cabinets. New York: Macmillan.

Press, Inc.

. (1997). Cabinets in West Europe. New York: St. Martin's

Blondel, J. y Thiébault, J. L. (1988). The Study of Western European Cabinets. European Journal of Political Research, 16 (2), 115-123.

(1991). The Profession of Government Minister in Western Europe. London: St. Martin's Press, Inc.

Boeninger, E. (1997). Democracia en Chile. Leccionespara la Gobernabilidad. Santiago de Chile: Editorial Andrés Bello.

Box-Steffensmeier, J. M. y Jones, B. S. (2004). Event History Modeling. A Guide for Social Scientists. New York: Cambridge University Press.

Breslow, N. E. (1974). Covariance Analysis of Censored Survival Data. Biometrics, 30 (1), 89-99.

Cabezas, L. M. (2011). Profesionalización de las Elites Parlamenterias en Bolivia, Colombia y Perú. POSTData, 16 (2), 223-258.

Camerlo, M. (2013). Gabinetes de Partido Único y Democracias Presidenciales. Indagaciones a partir del Caso Argentino. América Latina Hoy, 64, 119-142.

Camerlo, M. y Pérez-Liñán, A. (2015). Minister Turnover, Critical Events, and the Electoral Calendar in Presidential Democracies. The Journal of Politics, 77 (3), 608-619.

Canelo, P. (2011). Acerca de la construcción de carreras políticas en la Argentina. Los senadores nacionales en 1973, 1983 y 1989. PolHis, 4 (7), 140-153.

. (2014). Represión, Consenso y "Diálogo Político”. El Ministerio del Interior Durante la Última Dictadura Militar Argentina. 
Politica, Revista de Ciencia Politica, 52 (2), 217-239.

Chasquetti, D., Buquet, D. y Cardarello, A. (2013). La Designación de Gabinetes en Uruguay: Estrategia Legislativa, Jerarquía de los Ministerios y Afiliación Partidaria de los Ministros. América Latina Hoy, 64, 15-40.

Codato, A. (2015). Estado Novo no Brasil: Um Estudo da Dinâmica das Elites Políticas Regionais em Contexto Autoritário. Dados, Revista de Ciências Sociais, 58 (2), 305-330.

Cox, D. R. (1972). Regression Models and Life-Tables. Journal of the Royal Statistical Society. Series B (Methodological), 34 (2), 187-220. . (1975). Partial Likelihood. Biometrika, 62 (2), 269-276.

Cuevas, H., Morales, M., Rojas, J. y Aubry, M. (2015). Los Ministros de la Concertación de Partidos por la Democracia en Chile. Un Análisis de sus Capitales Político, Social y Cultural. América Latina Hoy, 71, 121-150.

Cummings, P. M. M. (2015). Democracy and Student Discontent: Chilean Student Protest in the Post-Pinochet Era. Journal of Politics in Latin America, 7 (3), 49-84.

Curtin, J. (2015). New Zealand: Stability, Change or Transition? Achieving and Retaining Ministerial Office. En Dowding, K. y Dumont, P. (Eds.), The Selection of Ministers around the World. New York: Routledge.

Dávila, M. (2010). Tecnocracia y Democracia en el Chile Contemporáneo: El Caso de los Gobiernos de la Concertación (1990-2010). Revista de Sociología, 24, 199-217.

. (2011). Tecnocracia y Política en el Chile Posautoritario (1990-2010). En Joignant, A. y Güell, P. (Eds.), Notables, Tecnócratas y Mandarines: Elementos de Sociología de las Elites en Chile (1990-2010). Santiago de Chile: Ediciones Universidad Diego Portales.

Dávila, M., Olivares, A. y Avendaño, O. (2013). Los Gabinetes de la Concertación en Chile (1990-2010). América Latina Hoy, 64, 67-94.

Delamaza, G. (2011). Elitismo Democrático, Líderes Civiles y Tecnopolítica en la Reconfiguración de las Élites Políticas. En Joignant, A. y Güell, P. 
(Eds.), Notables, Tecnócratas y Mandarines: Elementos de Sociología de las Elites en Chile (1990-2010). Santiago de Chile: Ediciones Universidad Diego Portales.

Dogan, M. (1981). La Selection des Ministres en Italie: Dix Règles NonEcrites. International Political Science Review, 2 (2), 189-209.

Dowding, K. y Lewis, C. (2015). Australia: Ministerial Characteristics in the Australian Federal Government. En Dowding, K. y Dumont, P. (Eds.), The Selection of Ministers around the World. New York: Routledge.

Efron, B. (1977). The Efficiency of Cox's Likelihood Function for Censored Data. Journal of the American Statistical Association, 72 (359), 557-565.

Espinoza, F. (2015). Bolivia: La circulación de sus élites (2006-2014). Santa Cruz de la Sierra: Editorial El País.

Espinoza, V. (2010). Redes de Poder y Sociabilidad en la Élite Política Chilena. Polis, Revista de la Universidad Bolivariana, 9 (26), 251-286.

Esquivel, G. y Larraín, F. (1999). América Latina frente a la Crisis Asiática. Estudios Públicos, 73, 5-30.

Garretón, M. A. (1999). Chile 1997-1998: The Revenge of Incomplete Democratization. International Affairs, 75 (2), 259-267.

Garrido, L. (2013). Elites, Political Elites and Social Change in Modern Societies. Revista de Sociología, 28, 31-49.

Giorgi, G. I. (2014). Los Factores "Extrapolíticos" de la Carrera Política: Una Aproximación a las Sociabilidades de los Ministros de la Nación en la Argentina (1854-2011). Política, Revista de Ciencia Politica, 52 (2), 241-273.

González-Bustamante, B. (2013a). El Estudio de las Élites en Chile: Aproximaciones Conceptuales y Metodológicas. Intersticios Sociales, 6, $1-20$.

. (2013b). Factores de Acceso y Permanencia de la Élite Política Gubernamental en Chile (1990-2010). Política, Revista de Ciencia Politica, 51 (1), 119-153. 

Nueva Arena Electoral en Chile. Política, Revista de Ciencia Política, 52 (2), 49-91.

(1990-2010). Mimeo.

. (2015). Postprint: Élite Politica Gubernamental en Chile

González-Bustamante, B. y Olivares, A. (2015). Trayectorias de Ministros y Subsecretarios en Chile durante los Gobiernos de la Concertación (1990-2010). Ponencia presentada en el VIII Congreso Latinoamericano de Ciencia Política, 22-24 de julio, Lima, Perú.

González-Bustamante, B., Olivares, A., Abarca, P. y Molina, E. (2016). Servicio Civil en Chile, Análisis de los Directivos de Primer Nivel Jerárquico (2003-13). Revista de Administração Pública. doi: $10.1590 / 0034-7612145767$

Gramacho, W. G. (2015). Ciclos de Crise de Imagem e a Influência da Imprensa na Sobrevivência Ministerial do Governo Dilma Rousseff (2011-2014): Uma Análise Preliminar. Ponencia presentada en el VIII Congreso Latinoamericano de Ciencia Política, 22-24 de julio, Lima, Perú.

Grambsch, P. M. y Therneau, T. M. (1994). Proportional Hazards Tests and Diagnostics Based on Weighted Residuals. Biometrika, 81 (3), 515-526.

Grindle, M. S. (2012). Jobs for the Boys: Patronage and the State in Comparative Perspective. Cambridge: Harvard University Press.

Higley, J. y Gunther, R. (1992). Elites and Democratic Consolidation in Latin America and Southern Europe. Cambridge: Cambridge University Press.

Higley, J. y Pakulski, J. (1992). Revolution and Elite Transformation in Eastern-Europe. Australian Journal of Political Science, 27 (1), 104-119.

Hosmer, Jr., D. W., Lemeshow, S. y May, S. (2008). Applied Survival Analysis. Regression Modeling of Time-to-Event Data. New Jersey: John Wiley \& Sons, Inc. 
Inácio, M. (2013). Escogiendo Ministros y Formando Políticos: Los Partidos en Gabinetes Multipartidistas. América Latina Hoy, 64, 4166.

Joignant, A. (2011a). El Estudio de las Élites: Un Estado del Arte. En Mella, M. (Ed.), Extraños en la Noche: Intelectuales y Usos Políticos del Conocimiento durante la Transición Chilena. Santiago de Chile: RIL Editores.

. (2011b). Tecnócratas, Technopolsy Dirigentes de Partido: Tipos de Agentes y Especies de Capital en las Elites Gubernamentales de la Concertación (1990-2010). En Joignant, A. y Güell, P. (Eds.), Notables, Tecnócratas y Mandarines: Elementos de Sociología de las Elites en Chile (1990-2010). Santiago de Chile: Ediciones Universidad Diego Portales.

. (2011c). The Politics of Technopols: Resources, Political Competence and Collective Leadership in Chile, 1990-2010. Journal of Latin American Studies, 43 (3), 517-546.

. (2012). Habitus, Campo y Capital. Elementos para una Teoría General del Capital Político. Revista Mexicana de Sociología, 74 (4), 587-618.

- (2014). El Capital Político Familiar: Ventajas de Parentela y Concentraciones de Mercado en las Elecciones Generales Chilenas 2013. Politica, Revista de Ciencia Política, 52 (2), 13-48.

Joignant, A. y González-Bustamante, B. (2014). El Núcleo de la Élite Politica Chilena 1990-2010. Mimeo.

Joignant, A. y Güell, P. (2011). Poder, Dominación y Jerarquía: Elementos de Sociología de las Elites en Chile (1990-2010). En Joignant, A. y Güell, P. (Eds.), Notables, Tecnócratas y Mandarines: Elementos de Sociología de las Elites en Chile (1990-2010). Santiago de Chile: Ediciones Universidad Diego Portales.

Kerby, M. (2015). Canada: Ministerial Careers. En Dowding, K. y Dumont, P. (Eds.), The Selection of Ministers around the World. New York: Routledge.

King, G., Alt, J. E., Burns, N. E. y Laver, M. (1990). A Unified Model of Cabinet Dissolution in Parliamentary Democracies. American Journal 
of Political Science, 34 (3), 846-871.

Levita, G. (2015). La Política como Profesión: Perfiles y Tipos de Trayectorias de los Senadores Argentinos. Telos, 17 (1), 38-57.

Lipset, S. M. y Solari, A. (1967). Elites in Latin America. New York: Oxford University Press.

Lobos, M. (2014). La Influencia de las Organizaciones Políticas Universitarias en la Formación de Élites Políticas en Chile: El Caso de las Federaciones de Estudiantes de la Universidad de Chile y Universidad Católica 1984-2005. Politica, Revista de Ciencia Política, 52 (2), 157-182.

Lodola, G. (2009). La Estructura Subnacional de las Carreras Políticas en Argentina y Brasil. Desarrollo Económico, 49 (194), 247-286.

Luna, J. P. y Zechmeister, E. J. (2005). Political Representation in Latin America: A Study of Elite-Mass Congruence in Nine Countries. Comparative Political Studies, 38 (4), 388-416.

Mainwaring, S. (1993). Presidentialism, Multipartism, and Democracy: The Difficult Combination. Comparative Political Studies, 26 (2), 198228.

Martínez-Gallardo, C. (2014). Designing Cabinets: Presidential Politics and Ministerial Instability. Journal of Politics in Latin America, 6 (2), $3-38$.

Masuyama, M. y Nyblade, B. (2015). Japan: Ministerial Selection and De-Selection. En Dowding, K. y Dumont, P. (Eds.), The Selection of Ministers around the World. New York: Routledge.

Milligan, G. W. y Cooper, M. C. (1985). An Examination of Procedures for Determining the Number of Clusters in a Data Set. Psychometrika, 50 (2), 159-179.

Montero, A. P. (2014). Brazil: Explaining the Rise and Decline of the Conservatives. En Luna, J. P. y Rovira, C. (Eds.), The Resilience of the Latin American Right. Baltimore: Johns Hopkins University Press.

Morresi, S. y Vommaro, G. (2014). Argentina: The Difficulties of the Partisan Right and the Case of Propuesta Republicana. En Luna, J. P. y 
Rovira, C. (Eds.), The Resilience of the Latin American Right. Baltimore: Johns Hopkins University Press.

Mustapic, A. M. (2000). "Oficialistas y Diputados": Las Relaciones Ejecutivo-Legislativo en la Argentina. Desarrollo Económico, 39 (156), 571-595.

Navia, P. (2004). Las Grandes Alamedas: El Chile Post Pinochet. Santiago de Chile: La Tercera Mondadori.

Oksanen, J. (2014). Cluster Analysis: Tutorial with R. Mimeo.

Olavarría, M. (2011). La Institucionalización y Gestión Estratégica del Acceso a la Información y la Transparencia Activa en Chile. Santiago de Chile: Banco Interamericano de Desarrollo; Consejo para la Transparencia.

Olivares, A., Baeza, J. y Dávila, M. (2015). Los Gabinetes Ministeriales en la Democracia Chilena Post-1990: Un Caso de Estabilidad, Continuidad Histórica y Negociación Inter-partidaria. Documentos y Aportes en Administración Pública y Gestión Estatal, 15 (24), 7-31.

Olivares, A. y González-Bustamante, B. (2015). Supervivencia de los Ministros y Subsecretarios en Chile (1990-2014). Ponencia presentada en el Congreso Internacional Élites y Liderazgo en Tiempos de Cambio, 10-11 de junio, Salamanca, España.

Olivares, A., González-Bustamante, B., Meneses, J. y Rodríguez, M. (2014). Los Think Tanks en el Gabinete: Una Exploración del Caso Chileno (2006-2014). Revista de Sociología, 29, 37-54.

O'Quigley, J., Xu, R. y Stare, J. (2005). Explained Randomness in Proportional Hazards Models. Statistics in Medicine, 24 (3), 479-489.

Quiroz, A. (2015). United States of America: The Cabinet. En Dowding, K. y Dumont, P. (Eds.), The Selection of Ministers around the World. New York: Routledge.

Ramió Matas, C. y Salvador, M. (2005). Servicio Civil en América Latina: Reflexiones y Propuestas Tentativas. Documentos y Aportes en Administración Pública y Gestión Estatal, 5 (6), 63-90.

Ramos, C. y Scrollini, F. (2013). Los Nuevos Acuerdos entre Políticos y Servidores Públicos en la Alta Dirección Pública en Chile y Uruguay. 
Revista Uruguaya de Ciencia Política, 22 (1), 11-36.

Rehren, A. (1992). Liderazgo Presidencial y Democratización en el Cono Sur de América Latina. Revista de Ciencia Política, 14 (1-2), 63-87.

. (2002). Clientelismo Político, Corrupción y Reforma de Estado en Chile. En Valdés, S. (Ed.), Reforma de Estado. Volumen II: Dirección Pública y Compras Públicas. Santiago de Chile: Centro de Estudios Públicos.

Reimer, J. (1970). Circulación de las Élites en Chile. Revista Latinoamericana de Ciencia Politica, 1 (2), 296-299.

Royston, P. (2006). Explained Variation for Survival Models. The Stata Journal, 6 (1), 83-96.

Royston, P. y Sauerbrei, W. (2004). A New Measure of Prognostic Separation in Survival Data. Statistics in Medicine, 23 (5), 723-748.

Siavelis, P. M. (2009). Enclaves de Transición y Democracia Chilena. Revista de Ciencia Política, 29 (1), 3-21.

Siavelis, P. M. (2013). El Éxito del Presidencialismo en Chile: Gabinetes, Asesores y Demás. En Alessandro, M. y Gilio, A. (Eds.), La Dinámica del Poder Ejecutivo en América: Estudios Comparados sobre la Institución Presidencial. Buenos Aires: Instituto Nacional de la Administración Pública.

. (2014). Chile: The Right's Evolution from Democracy to Authoritarianism and Back Again. En Luna, J. P. y Rovira, C. (Eds.), The Resilience of the Latin American Right. Baltimore: Johns Hopkins University Press.

Silva, P. (2006). Los Tecnócratas y la Política en Chile: Pasado y Presente. Revista de Ciencia Política, 26 (2), 175-190.

. (2010). En el nombre de la razón: Tecnócratas y políticos en Chile. Santiago de Chile: Ediciones Universidad Diego Portales.

. (2011). La Elite Tecnocrática en la Era de la Concertación. En Joignant, A. y Güell, P. (Eds.), Notables, Tecnócratas y Mandarines: Elementos de Sociología de las Elites en Chile (1990-2010). Santiago de Chile: Ediciones Universidad Diego Portales. 
Solimano, A. (2014). Economic Elites, Crises, and Democracy: Alternatives beyond Neoliberal Capitalism. New York: Oxford University Press.

Somma, N. y Bargsted, M. (2015). La Autonomización de la Protesta en Chile. En Cox, C. y Castillo, J. C. (Eds.), Aprendizaje de la Ciudadanía. Contextos, Experiencias y Resultados. Santiago de Chile: Ediciones Universidad Católica de Chile.

Therneau, T. M. y Grambsch, P. M. (2000). Modeling Survival Data: Extending the Cox Model. New York: Springer.

Tricot, T. (2012). Movimiento de Estudiantes en Chile: Repertorios de Acción Colectiva ¿̇Algo Nuevo? Revista F@ro, 15, 1-12.

Uriarte, E. (1997). El Análisis de las Élites Políticas en las Democracias. Revista de Estudios Políticos (Nueva Época), 97, 249-275.

Vittinghoff, E. y McCulloch, C. E. (2006). Relaxing the Rule of Ten Events per Variable in Logistic and Cox Regression. American Journal of Epidemiology, 165 (6), 710-718.

Recibido: 14-10-2015

Aceptación de la versión final: 18-12-2015 